International Journal of Instruction e-ISSN: 1308-1470 • www.e-iji.net

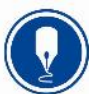

October $2019 \bullet$ Vol.12, No.4

p-ISSN: 1694-609X

pp. $719-732$

Received: 28/01/2019

Revision: 09/07/2019

Accepted: 14/07/2019

OnlineFirst:12/09/2019

\title{
Using the C-K theory to develop student's creativity: A Case Study of Creative University
}

\section{Mayuree Suacamram}

Baise University, China \& Bangkok University, Thailand, 2464135932@qq.com \& mayuree.s@bu.ac.th

Creativity is essential for everyone; it will be one of their valuable assets that will become beneficial their organization. This study aims to develop a series of workshop classes to promote learners' creativity based on the C-K theory. This research method uses pretest-posttest control group design. The research is divided into three stages: stage 1: gathering preliminary data by exploring opinions of experts regarding developing creativity, stage 2: developing lesson plans by creating lesson plans from the analysis of the data from stage 1 , then validating them by experts and piloting them, stage3: examining the results of implementing the lesson plans by analyzing data using repeated measures and multi-level analysis. The findings reveal that the lesson plans aim to develop creativity in learners through designing projects, or other type of work, activities based on C-K theory together with a five-class course called Design and Visualization for Film starting from 1) photo design 2) identifying and formulating problems 3) Reviewing problems 4) Creating a photo design based on $\mathrm{C}-\mathrm{K}$ theory and 5) designing a film poster based on $\mathrm{C}-\mathrm{K}$ theory. The findings of the implementation show that the learner group who was taught by using C-K theory presented higher degree of creativity development than those who were not.

Keywords: developing creativity, C-K theory, undergraduate student, lesson plan, creative university

\section{INTRODUCTION}

Creativity is critical for every organization because creativity is the source of innovations, new products, new services or solutions to complex problems. Creativity is an ability to produce and develop work, theory, techniques or ideas. Creativity is individual imaginations or expressions resulting from integrating knowledge and experiences form ideas or hypotheses and then those hypotheses are testing them to verify a new discovery (VandenBos, 2007 ;Torrance, 2008). Many research articles revealed that creativity of employees contributes to work processes, steps, strategies, workloads, products and services of their organizations, which essentially brings a

Citation: Suacamram, M. (2019). Using the C-K theory to develop student's creativity: A Case Study of Creative University. International Journal of Instruction, 12(4), 719-732. https://doi.org/10.29333/iji.2019.12446a 
competitive advantage to their organizations (De Stobbeleir, Ashford \& Buyens, 2011; Oldham \& Cummings, 1996). If there is a method that would help develop creativity in individuals, particularly during pre-working ages, it will be a great benefit to both the individuals and the future organizations they will be working for.

This study was conducted in a 'Creative University'. The university provides courses with an emphasis on encouraging learners to develop their creativity. The majority of courses focus on developing creativity through several assignments involving creating designs, new products, new services or solutions which allow the learners to express their creativity. The "Design and Visualization for Film" Course is a very important course for the third-year undergraduate students majoring in Film. This course provides learning activities for students to design their photos and to develop their skills in designing movies. Previously even though students were able to produce creative designs, they felt short of showing a systematic thinking process (Urupong Phaetkacha, 2017). Therefore, it is crucial to teach students' a thinking process when it comes to develop their creativity.

The C-K theory is a systematic principle that is used to design products, services or solutions by reviewing the basic ideas of design. If a new idea is analyzed, categorized and reviewed systematically, the new idea will become a creative idea that is qualified and feasible. Therefore, the $\mathrm{C}-\mathrm{K}$ theory is a tool for generating creative ideas in design. To apply the C-K theory is to focus on realistic ideas and monitoring ideas based on Concept: $\mathrm{C}$ and Knowledge: K. Ideas will lead to steps in determining problems, drafting solutions and monitoring (Reich et al, 2012; Ribiere, 2013). Many research studies applied the C-K theory to designing and analyzing process for success (Hatchuel et $\mathrm{al}, 2016)$. Some researchers used the C-K theory to analyze the Advanced Systematic Inventive Thinking (ASIT) of high school and university students by giving an exercise for students to design an object. After teaching ASIT for several hours, students were able to use ASIT to successfully solve problems (Kolberg et al, 2007).

This study put a theory and principles into practice applying the C-K theory to create workshop lesson plans for developing creativity for a group of third-year undergraduate students in the "Design and Visualization for Film" Course. To examine the effectiveness of the lesson plans, the achievement scores obtained by the experimented group and the control group were compared. In addition, the researcher explored the learning outcomes of the third-year vocational students majoring in the architecture who exchanged their feedback after they were taught the developed lessons. Finally, the study resulted in lesson plans for developing learners' creativity can be implemented in academic institutions or related organizations.

\section{REVIEW OF LITERATURE}

\section{Concepts about Creativity}

Many researchers have defined 'creativity' as novel ideas which show identity and originality or subsequent ideas that were built on any previous ideas. Creativity is useful, practical, relevant and accepted in a particular context. It can be used to solve problems very well (Barbot, Lubart \& Besancon, 2016; Gardner, 1993; Hallman, Wright \& Conger, 2016). 
Torrance (1990) divided creativity into 5 components: 1) Fluency which means the number of relevant ideas showing ability to generate quantity of figural images 2) Originality which means ability to generate uncommon unique ideas. To identify originality, a comparison of statistics rating the most common idea (the same ideas as generated by general people) will be scored as 0 while ideas that match with the criteria set will be scored as 1.3) Elaboration which means expansion of ideas as seen from the number of additional subsequent ideas showing ability to develop more refined ideas. 4) Abstractness of Titles which means ideas beyond written explanation which is considered abstract creativity. This shows moving beyond concreteness 5) resistant to premature closure which means open-mindedness in psychology. It is believed that creative behaviour involves considering diversity of the information for data processing and staying open-minded.

There are many concepts for developing creativity such as Wallas' Four-stage Model and CPS Model (Creative Problem Solving) are the processes of developing a person's creativity (Wallas, 1926; Osborn, 1964). In addition, Renzulli (2016) addresses the three-Ring Conception which is the main dimensions of human potential for creative productivity. Three interacting clusters of trait rings include Above Average Ability, Task Commitment, and Creativity.

Renzulli (2016) also addresses knowledge to promote creativity which blends three levels. The first level is Received Knowledge, most often associated with what traditional schooling which is typically conveyed to students through lectures, textbooks, worksheets, and various types of digital media. The second level is Analyzed Knowledge, develops thinking skills such as interpreting, extrapolating and recognizing attributes. Classroom practices are discussions, debates, simulations, role-playing, critiquing, and questioning that focus on why, how, and cause-and-effect. Analyzed Knowledge interacts with Received Knowledge in a cyclical manner. The third level is Applied and Created Knowledge, are the ability to solve problems that create meaning for the individual and improve the powers of mind. Not only there are the concepts of creative development mentioned above, but also there is another concept, C-K theory, which is a systematic development of creativity.

\section{Developing Creativity Based on C-K Theory}

The $\mathrm{C}-\mathrm{K}$ theory is a systematic practice for designing products, services or solutions by reviewing abstract ideas (Ribiere, 2013; Reich et al, 2012). New ideas will be analyzed, categorized and reviewed systematically in the Concept Space and Knowledge Space. The Knowledge Space is something that exists in this world. It includes relevant information about techniques, commerce, society, rules and regulations, etc. As for the Concept Space, it is something that doesn't exist in this world. It could be something illogical, surreal or fantasy such as flying boats or cars with no wheel, etc. These things are the beginning of the design process in the Knowledge Space and cannot be used to directly solve the problems. (Hatchuel et al., 2016) Designing based on the C-K Theory consists of the following steps (Reich et al, 2012):

1. Define the primary concepts and compile all of the ideas. Then classify the concepts into two categories: a) all of the attributes and b) if the ideas in the Concept Space are 
acceptable for the Knowledge Space, the design will be stopped. Those filtered ideas are based on the knowledge from the K Space and the exchanging of ideas between the $\mathrm{C}$ and the $\mathrm{K}$ Space as seen in the following figure.

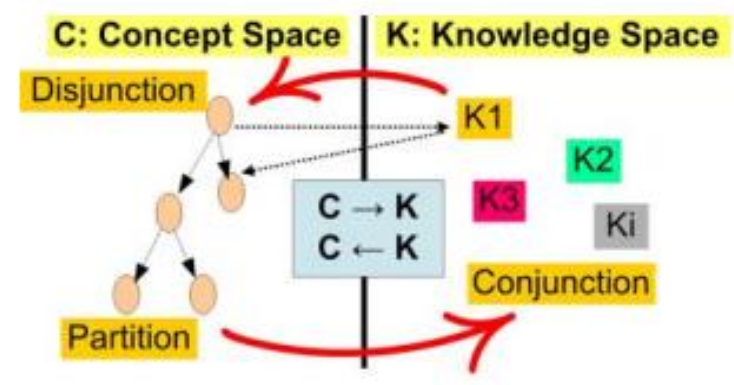

Figure 1

C-K Design Process and Its Operators

Source: Hatchuel et al (2016).

2. Propositions in the Concept Space are necessities of creativity. The creative design process requires changing the unacceptable features in the $\mathrm{C}$ to become acceptable.

3. Designed propositions must be composed within an opened scope. Unacceptable and unrealistic propositions cannot be transferred to the K Space.

4. The creative design process needs both expansion (ideating) in the $\mathrm{C}$ Space and $\mathrm{K}$ Space. There are four operators. Each operator answers a different question as indicated: 1) $\mathrm{K} \rightarrow \mathrm{C}$ : After you have gained knowledge, how could you expand ideas in the $\mathrm{C}$ Space? 2) $C \rightarrow C$ : How can Ideas in the $C$ Space be expanded? 3) $K \rightarrow K:$ Does any existing knowledge need expansion? And 4) $\mathrm{C} \rightarrow \mathrm{K}$ : Which of the ideas in the $\mathrm{C}$ Space are acceptable and feasible?

\section{Related Studies Regarding Creativity Development}

A research study conducted by Loudon \& Deininger (2014) investigated design thinking and developed a concept/model for creativity development called the LCD model. The model consists of three circles, Circle no. 1 is listening, which means listening, observing and realizing the existence of self and others. Circle no. 2 is connecting, which means opening and be attentive to new concepts and opportunities, the main components of accepted creativity. Circle no. 3 is doing, which refers to exploring, experimenting and creating a prototype.

Related studies about creativity development of learners reveal that teacher plays a vital role in establishing relationship with the learners to foster creativity. Shibuya (2013) indicated that teacher can promote creativity when the teacher and learners collaborate to create a new discovery. The process of making a new discovery starts with 1) Mining of relationship, 2) Learning Through Accident 3) Showing the Art of Creation 4) The Challenging Point. The process is consistent with the key features of learning environment that fosters creativity proposed by Cole, Sugioka, \& Yamagata-Lynch (1999). The following explains the key features: 
1) The relationship between teacher and students illustrates the attempt to develop knowledge and wisdom of the learners.

2) Learning evaluation should be performed without the use of exams but by considering how creatively problems are solved, the number of submitted assignments and the analysis of process writing.

3) Teacher should be open-minded by allowing the students freedom to select answers. This is to stimulate various ideas and always emphasizing that there is no absolute correct answers allow different perspectives to be expressed freely.

4) For In-class activities, students should be allowed to come up with different ideas. Brainstorming and discussing ideas should be conducted before reaching the consensus.

Based on the review of the related literature, the following is the framework for this study.

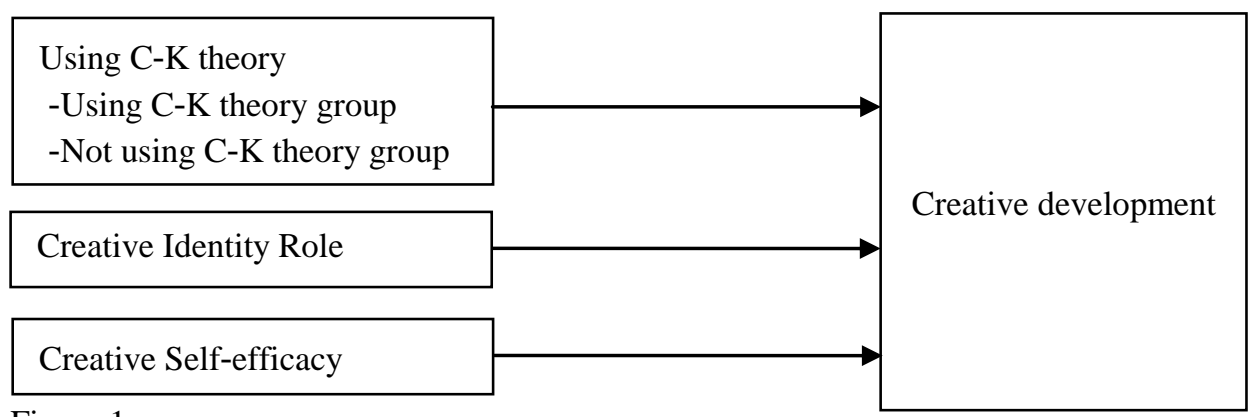

Figure 1

Framework of the study

This study aims to develop a series of workshop classes to promote learners' creativity based on the $\mathrm{C}-\mathrm{K}$ theory. There are three sub objectives as follows:

1) To gather preliminary data to create lesson plans for the workshop to develop creativity based on the $\mathrm{C}-\mathrm{K}$ theory.

2) To develop the lesson plans for developing creativity based on the C-K theory.

3) To examine the results of developing creativity after implementing the lesson plans between using $\mathrm{C}-\mathrm{K}$ theory group and not using $\mathrm{C}-\mathrm{K}$ theory group.

\section{METHOD}

This research method uses the pretest-posttest control group design. The research process is as follows.

\section{Stage1: Gathering preliminary data by exploring opinions of experts}

The first stage began with 1) reviewing related literature regarding creativity development. 2) A survey was conducted to collect data about students' opinions about creativity development. Next 3) Data collection about experts' opinions on creativity development was conducted. 4) The data was analyzed and summarized. 
The informants were divided into two groups: 1) Group1 consists of the 62 experts in the field of creativity development. The criteria for expert selection were as following: 1.1) they obtained a Master's degree in various fields regarding creativity 1.2) they have work experience regarding creativity for at least 5 years. And 1.3) they have received an award regarding creativity. 2) Group 2 consists of 6,755 undergraduate students at a creative university.

The research instruments were interview questions about how to provide environment, activities to foster creativity, how to develop creativity, and opinions about using the $\mathrm{C}-\mathrm{K}$ theory to develop creativity. The data was triangulated, coded and analyzed by doing content analysis. Then, the findings were used to develop the lesson plans for the workshop.

\section{Stage 2: Developing the lesson plans based on the C-K theory}

This stage started with 1) using the findings from stage 1 to create a draft of the lesson plans. Next, 2) the lesson plans were validated by experts and piloted with a piloted group of students. Then, 3 ) the lesson plans were revised according to the feedback from the experts. Finally, 4) the lesson plans were tried out with a piloted group of students.

The informants were divided into two groups: 1) Group 1 consisted of 3 experts in the field of creativity development. The criteria for expert selection were same stage 1 and 2) Group 2 consisted of 5 third-year undergraduate students from the school of Media Digital and Film. They were the students in the piloted group.

The research instrument was the form to evaluate the lesson plans. The form has four main criteria topics: 1) goals and objectives for development, 2) content, 3) activities and teaching/learning materials and 4) learning assessment and evaluation. A content analysis was carried out and the findings were used for revising the lesson plans.

\section{Stage 3: Examining the results of creativity development after implementing}

This stage started with 1) preparing an instrument, 2) conducting the experiment to implement the lesson plans, collecting data and 3) analyzing and summarizing the data.

The informants were divided into two student groups: 1) Student Group 1 consists of 14 undergraduate students who took the "Design and Visualization for Film" Course using the developed lesson plans based on the C-K theory and 2) Student Group 2 consists of 11 undergraduate students who took the "Design and Visualization for Film" Course using regular lesson plans.

The research instruments were as follows:

1. A creativity test adapted from Torrance's creativity components (Kim, 2006). The test was later revised using the findings from stage 1 ,

2. Rubric assessment to evaluate the students' creativity from their assignments. The evaluation criteria consist of the 6 creativity components as appeared on the revised test. Three experts, the same experts who had participated in stage 1-2.

3. Creative role identity using 4 questions from Jaussi, Randel and Dionne (2007). The Cronbach's alpha of the assessment test was 0.732 . 
4. Creative Self-efficacy using 6 questions from Karwowski, Lebuda, Wisniewska, \& Gralewsk (2013). The Cronbach's alpha of the assessment test was 0.718.

In terms of data analysis, a comparison of creativity development between the two student groups was using repeated measurement with Independent Variable (IV). Later, multi-level analysis was carried out to examine multi-level effect of the student groups, creative role identity and creative self-efficacy toward creativity.

\section{FINDINGS}

\section{Preliminary Data to Create Lesson Plans Based on the C-K Theory}

The insights which were used as a basis to develop the lesson plans for creativity development according to the $\mathrm{C}-\mathrm{K}$ theory are summarized as follows:

\section{The definition and components of creativity}

Creativity consists of 6 elements: 1) originality which means tools, processes or ability to think differently or thinking outside the box without relying on any social rules/regulations. 2) building on existing ideas which means ideas that are not completely new but have been developed or upgraded from the existing ideas. 3) usefulness which refers to practical thinking process beneficial for the thinker, society and other people 4) positive thinking which refers to transforming suffering to happiness both in life and work 5) Man-made imagination which refers to untraditional imaginaries or thoughts without any rule or framework governed 6) uniqueness which refers to unique ideas showing self-identity different from others. Apart these 6 features, the findings from the survey revealed that majority of the undergraduate students define creativity as new ideas and building-on from existing ideas respectively.

\section{Developing creativity by using the $\mathrm{C}$-K theory}

Regarding this topic, the researcher would like to propose three observations:

1) Developing creativity is non-logical thinking outside the box on Concept Space and helps ideate new, strange ideas under limitations in the Knowledge Space and is a thinking tool such as other thinking tools. For example, start with divergent thinking and then following by convergent thinking.

2) Additional issues that should be included in the C-K theory are a) expanding the imagine space in the Concept Space b) sharing ideas with other people and c) taking social responsibility in to account: Long-term impacts should be taken into consideration when trying to come up with a solution.

3 ) It is found out that the use of C-K theory might not be inappropriate if the teacher and students do not completely understand the process of $\mathrm{C}-\mathrm{K}$ theory. Rather than enhancing the thinking process, thinking can be interrupted and blocked by the overemphasis of $\mathrm{C}$ K theory.

\section{Lesson Plans for Creativity Development Based on the C-K Theory}

Content of the lesson is suitable for the third-year or higher undergraduate students, passed general education courses and core courses of their major. The developed lesson plan aims to develop learners' creativity through the creation of projects that requires 
designing process. An example of courses is the "Design and Visualization for Film" Course. The following table shows activities for each class.

Table 1

Lesson Activities to Develop Creativity Based on the C-K Theory

\begin{tabular}{|c|c|c|c|c|}
\hline No. & Topic & Introduction & The main lesson & Wrap-up \\
\hline 1 & $\begin{array}{l}\text { Designing } \\
\text { photos based } \\
\text { on } \mathrm{C}-\mathrm{K} \text { theory }\end{array}$ & $\begin{array}{l}\text { Explaining } \\
\text { definitions of } \\
\text { creativity }\end{array}$ & $\begin{array}{l}\text {-Explaining principle of } \\
\text { C-K } \\
\text { - Explaining related } \\
\text { content such as colour } \\
\text { tones, etc. } \\
\text {-practicing designing } \\
\text { photos simultaneously } \\
\end{array}$ & $\begin{array}{l}\text {-summarizing } \mathrm{C}-\mathrm{K} \text { theory used } \\
\text { in photo design } \\
\text {-Giving assignment no. 1: } \\
\text { designing a photo according to } \\
\text { different colour tones. }\end{array}$ \\
\hline 2 & $\begin{array}{l}\text { Questioning } \\
\text { and designing } \\
\text { photos using } \\
\text { the C-K theory }\end{array}$ & $\begin{array}{l}\text { Reviewing the } \\
\text { definitions of } \\
\text { creativity and } \\
\text { telling the } \\
\text { students that they } \\
\text { have creativity. }\end{array}$ & $\begin{array}{l}\text {-explaining the principle } \\
\text { of questioning according } \\
\text { to C-K. } \\
\text {-explaining photo } \\
\text { composition } \\
\text {-practicing designing } \\
\text { photos that reflect their } \\
\text { identity using C-K theory }\end{array}$ & $\begin{array}{l}\text {-Summarizing the questioning } \\
\text { in the C-K theory } \\
\text {-Giving assignment no } 2 \text { : } \\
\text { designing photos that reflect } \\
\text { their identities. }\end{array}$ \\
\hline 3 & $\begin{array}{l}\text { Reviewing the } \\
\text { questioning } \\
\text { and designing } \\
\text { photos based } \\
\text { on the } \\
\text { C-K theory }\end{array}$ & $\begin{array}{l}\text { Discussing the } \\
\text { previous } \\
\text { assignments. } \\
\text { Students should } \\
\text { be able to take } \\
\text { feedback } \\
\text { constructively. }\end{array}$ & $\begin{array}{l}\text {-Having the students } \\
\text { design photos that reflect } \\
\text { their identities in three } \\
\text { different alone time shots } \\
\text { under guidance of the } \\
\text { teacher }\end{array}$ & $\begin{array}{l}\text {-Summarizing how to apply the } \\
\text { C-K theory in the assignment no. } \\
1-2 \\
\text {-Giving assignment no. } 3 \text { : } \\
\text { designing photos that reflect } \\
\text { their identities in three different } \\
\text { times. }\end{array}$ \\
\hline 4 & $\begin{array}{l}\text { Having the } \\
\text { students use } \\
\text { the C-K theory } \\
\text { to design } \\
\text { photos }\end{array}$ & $\begin{array}{l}\text { - Asking the } \\
\text { students to boost } \\
\text { their self- } \\
\text { confidence } \\
\text { believing that } \\
\text { they have } \\
\text { creativity. }\end{array}$ & $\begin{array}{l}\text {-Teacher explains the } \\
\text { principle and steps of C-K } \\
\text { theory and how to apply } \\
\text { the theory to students . } \\
\text {-University students } \\
\text { demonstrate how to use the } \\
\text { C-K theory in photo design } \\
\text {-University students train } \\
\text { the high school students to } \\
\text { take a self-portrait photo } \\
\text { and design a toilet. }\end{array}$ & $\begin{array}{l}\text {-University students summarize } \\
\text { how to use the C-K theory in } \\
\text { designing a self- portrait photo } \\
\text { and a toilet. } \\
\text {-Giving assignment no. } 4 \text { : } \\
\text { taking a self-portrait photo of } \\
\text { high school students and design } \\
\text { a toilet }\end{array}$ \\
\hline 5 & $\begin{array}{l}\text { Designing film } \\
\text { posters using } \\
\text { the C-K } \\
\text { theory. }\end{array}$ & $\begin{array}{l}\text {-Reviewing } \\
\text { related literature } \\
\text { such as movie } \\
\text { scripts. }\end{array}$ & $\begin{array}{l}\text {-creating a film poster } \\
\text { based on their movie script }\end{array}$ & $\begin{array}{l}\text {-Teacher and students help } \\
\text { summarize how to use the C-K } \\
\text { theory to design } \\
\text { - Giving assignment no. } 5 \text { design } \\
\text { a poster based on a movie script }\end{array}$ \\
\hline
\end{tabular}

\section{Results of Creativity Development After Implementation \\ Comparison of creativity development between student groups}

Student group 1, who were taught the C-K theory obtained higher mean score of creativity in assignment no.1-5 than student group 2, who were not taught the C-K theory. The reason is student group 1 had been taught the C-K theory before they were given the assignment no. 1. The range of the mean score of creativity that group 1 obtained in assignment no. 1 was $7.361-11.779$ out of 15 point (the full score). Group 2 obtained the mean score of creativity ranging from $5.872-10.095$ points. Gradual 
increase in the scores for creativity development in all of the 5 assignments obtained by Group 1 can be observed. The increase rates between each assignment are $19.44 \%$, $14.65 \%, 4.37 \%$ and $11.97 \%$ respectively. As for group 2, the increase rates are $16.31 \%$, $9.02 \%, 7.10 \%$ and $26.58 \%$ respectively (figure 2 ).

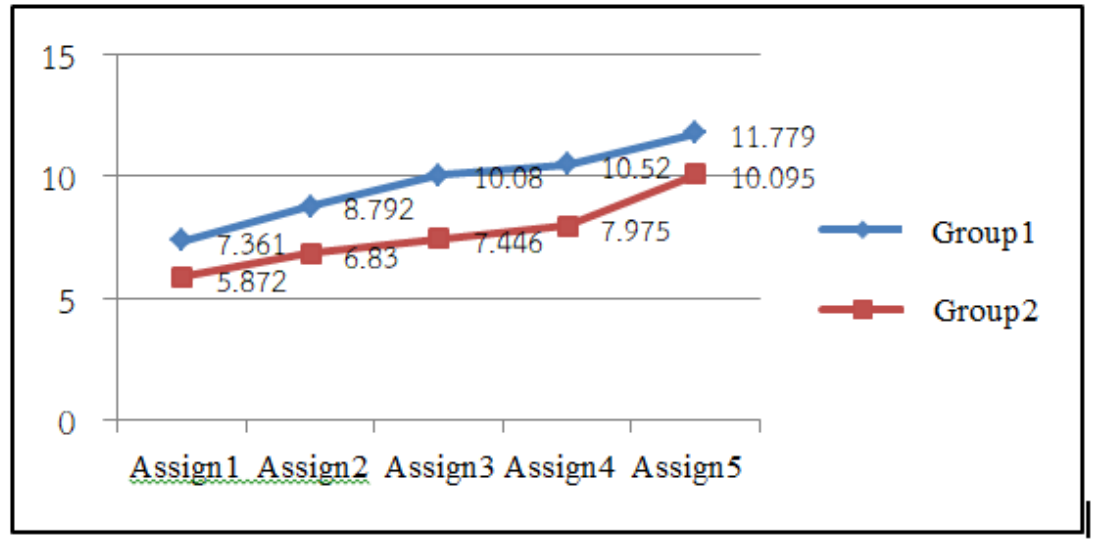

Figure 2

Scores for Creativity Development of the Two Groups

Assumption testing prior to analysis of repeated measurement with IV revealed that the variance co-variance matrices are significantly different statistically (Box's M $=34.856$ $\mathrm{P}=0.046$ ). The matrices of the coefficient values of the mean scores of the 5 assignments are not identity matric (Bartlett's test $=96.811 \mathrm{P}=0.000$ ) and the variance co-variance matrices are not identity matrices (Mauchly's test $=0.136 \mathrm{P}=0.000$ ). The trend analysis shows a linear trend.

The analysis of repeated measurement with IV shows the variance co-variance matrices are not identity matrices. Greenhouse-Geisser, Huynh-Feldt and Lower-bound correction were carried out. The result of the variance of the repeated measure shows that there were significant differences between each of the creativity scores due to the number of measure $(\mathrm{F}=40.199 \mathrm{P}=0.000)$. The trend analysis shows that the measurement shows a linear trend. The student groups demonstrated significant difference in their creativity development $(\mathrm{F}=15.462 \mathrm{P}=0.001)$ To conclude, the students who were taught the $\mathrm{C}-\mathrm{K}$ theory were able to achieve higher scores in all of the five assignments than those whose weren't taught the C-K theory.

\section{Multi -level analysis}

Multi-level analysis aims to find the size of the cross-level effect of the student groups, creative Role Identity and Creative Self-Efficacy. The sample consisted of 25 students. 5 assignments completed in 5 different times were used to assess creativity of each individual. The creativity scores of each of the five students were called with-individual data. Another was called individual-level data which is the combining results of Student Group1 $\left(\mathrm{C}_{\mathrm{ij}}\right)$. 2) Creative Role Identity (CRI) and 3) Creative Self-Efficacy (CSE). The following shows the formula of the Multi-level analysis. 
with-individual data: $\mathrm{C}_{\mathrm{ij}}=\beta_{\mathrm{oj}}+\mathrm{r}_{\mathrm{ij}}$

individual-level data: $\beta_{\mathrm{oj}}=\gamma_{00}+\gamma_{01}$ (group1) $+\gamma_{02}(\mathrm{CRI})+\gamma_{03}(\mathrm{CSE})+\mathrm{u}_{\mathrm{oj}}$

The coefficient value of the student group 1 on the mean score of creativity is greater than 0 showing statistical significance $(t=4.148, P=0.000)$. This means that the student group 1 achieved higher mean score of creativity than student group 2 . The coefficient is 2.253 .

The coefficient value of the creative role identity and creative self-efficacy on the mean score of creativity is not equal to 0 showing no statistical significance $(P>0.05)$. It can be said that creative role identity and creative self-efficacy have no effect on the differences in the mean scores of the creativity (Table 2).

Table 2

The Result of the Multi-Level Analysis of the Creativity Score of Student Group 1, Creative Role Identity and Creative Self-Efficacy

\begin{tabular}{llllll}
\multicolumn{1}{c}{ Fixed effect } & Coefficient & SD & $\mathrm{t}$ & $\mathrm{df}$ & $\mathrm{P}$ \\
\hline The total average $\left(\gamma_{\mathrm{oo}}\right)$ & 8.656 & 0.262 & 33.015 & 21 & 0.000 \\
Effect of student group 1 $\left(\gamma_{01}\right)$ & 2.253 & 0.543 & 4.148 & 21 & 0.000 \\
Effect of Creative Role Identity $\left(\gamma_{02}\right)$ & -0.223 & 1.006 & -0.222 & 21 & 0.827 \\
Effect of Creative Self-Efficacy $\left(\gamma_{03}\right)$ & 0.961 & 0.793 & 1.211 & 21 & 0.239 \\
\hline Random effect & Variance & $\mathrm{df}$ & $\chi^{2}$ & $\mathrm{P}$ & \\
Error $\left(\mathrm{U}_{\mathrm{oj}}\right)$ & 0.835 & 21 & 40.825 & 0.006 \\
Residual $\left(\mathrm{r}_{\mathrm{ij}}\right)$ & 4.420 & & & & \\
\hline
\end{tabular}

Findings from the analysis using the One-way Random Effect ANOVA Model and the Mean as Outcome Regression Model show the lower of variance from 1.901 to 0.835 due to the difference in Within-Subjects Effects, which is equal to $56.076 \%$. It could be said that being taught the lessons based on the $\mathrm{C}-\mathrm{K}$ theory, creative role identity and creative self-efficacy can be used to explain $56.076 \%$ of the variance of creativity. If all of the 3 variables are kept constant and considering the variance between the difference in mean score of individuals (the variance is 0.835 ) and the difference in each measure (the variance is 4.420), it is found the variance of mean score of individuals is $18.891 \%$ of all of the variance. Therefore, it suggests further studies can be conducted to find out about some other independent variables that could affect learners' creativity.

In conclusion, the mean score of creativity obtained by student group 1 was higher than the mean score of creativity obtained by student group 2 . Creative role identity and creative self-efficacy have no effect on the difference in the mean scores. All of the three variables can be used to explain $56.076 \%$ of the variance in the mean score of the creativity. If all of the 3 variables are kept constant, there still is $18.891 \%$ of the variance in the creativity that can be explained by other variables.

\section{DISCUSSION}

\section{Lesson plans for developing creativity include activities that allowed students to} understand clearly about creativity

The first trial implementation of the lesson plans based on the C-K theory showed that many of the students were not quite clearly understand the principle and the steps of 
designing based on the C-K theory. Even though the teacher demonstrated how to apply the $\mathrm{C}-\mathrm{K}$ theory to design and provided a photo-design activity for students to practice, it was found out during the practice that half of the students couldn't design a photo using the C-K theory. Later, the plan was adjusted to have the teacher work collaboratively with the students to do the assignment no. 1. The teacher posed several questions to ignite new ideas from the students constantly throughout the activity until the design was successful and satisfactory. This process alike Wallas' Four-stage Model and CPS Model which are the sequential process of developing creativity (Wallas, 1926; Osborn, 1964). The adjustment of the plan to have the teacher and students work together is consistent with Shibuya's idea (2013) that learning activities that foster team collaboration between teacher and learners to create new things enhance learners' creativity. Cole, Sugioka, \& Yamagata-Lynch (1999) also shared similar point of view stating that the key element that promotes learners' creativity is an attentive relationship between teacher and leaners focusing on development of knowledge and wisdom of the learners.

There are 4 guidelines for applying the $\mathrm{C}-\mathrm{K}$ theory to enhance creative development for undergraduate courses. Courses that are suitable to apply the $\mathrm{C}-\mathrm{K}$ theory are:

1) Courses which focus on free design: Students are allowed to openly express their ideas or to work on their design freely under minimum knowledge frameworks or conditions such as courses about product design or project design, etc.

2) Courses which focus on design under certain obligations: students design their creations based on certain principles or academic theories such as courses about research, marketing strategic planning, etc.

3) Courses that rely on memorization: students design strategies to help them memorize certain rules or content such as courses about laws or history, etc.

4) Courses that focus on practices and calculation: student cannot use the C-K theory for this kind of courses due to the nature and the structure of the courses that are fixed and unchangeable such as courses about drawing, drafting, calculus, statistics of research, etc. Using C-K theory in these subjects can't design ideas on the Concept space according to the imagination of the creators. Because of the idea must be in accordance with the rules, formulas, or conditions of that course. Teacher should consider the nature of assignments before apply the C-K theory to enhance learners' creativity.

\section{Lesson implementation based on the $\mathrm{C}$-K theory to develop learners' creativity}

Students, taught the C-K theory were able to develop creativity better than those who weren't taught the theory. The reason is that the C-K theory involving transferring ideas between the C Space and the K Space in order to generate new ideas (Hatchuel et al, 2016). It is consistent with the definition of creativity proposed by the two following groups of scholars. The first group defined creativity as novel and useful (Barbot, Lubart \& Besancon, 2016; Guilford, 1987; Mumford, 2003) while the second group pointed out that creativity is connecting ideas, establishing interaction and restructuring (Plucker, Begetto \& Dow, 2004; Treffinger, Isaksen \& Dorval, 1996). 
The C-K theory is one systematic framework for designing products or solutions by reviewing new abstract ideas. The design process begins with identifying problems and searching information in the Knowledge Space. The next step is to ideate in the Concept Space. The ideas generating in the Concept Space will be reviewed. Then, information in the Knowledge Space will be expanded in order to generate new ideas in the Concept Space (Ribiere, 2013; Reich et al, 2012). Previous studies adopted the C-K theory in Advanced Systematic Inventive Thinking: ASIT in many ways such as designing estimators, comparing theories in historical perspectives, analyzing and evaluating project practices, studying tools for industrial design (Hatchuel et al, 2016). It can be said that the $\mathrm{C}-\mathrm{K}$ theory is used as a tool for various complicated system analyses. C-K theory is consistent with Renzulli (2016) that uses knowledge to develop creativity.

\section{CONCLUSION}

Creativity is a new idea for a creator to create and design a something better. C-k theory is a tool that supports the creator in exploring a new idea by using the knowledge to base their own idea. This research found out that before the developing creativity of students, the teacher should understand the student that creativity isn't only about a new idea but it also included 6 dimensions such as 1) originality 2) building on existing ideas 3) usefulness 4) positive thinking 5) Man-made imagination and 6) uniqueness. However, students should practice thinking outside the box to motivate their own creativity. Using $\mathrm{C}-\mathrm{K}$ Theory for developing student creativity in the first step, the teacher needs to explain about $\mathrm{C}-\mathrm{K}$ theory process and show them an example of a simple product. After that let students try to design a product and regularly ask students question, let them discover a new idea together in concept space and let them search by their own in knowledge space. In further teacher should review C-K theory to students after that teacher should give them some exercise for students to design their own product by themselves. The teacher should look around and give students some advice. The exercise that gave to students should be challenged to the new idea.

\section{SUGGESTIONS}

1. The C-K theory is recommended for developing learners' creativity through designing creations. The creations here can be any objects, products, services, process or any methods of doing something. To come up with a creation, the $\mathrm{C}-\mathrm{K}$ theory should be applied. The thinking process according to the $\mathrm{C}-\mathrm{K}$ theory is summarized below:

1) Determining problems/requirements/ goals of a particular creation.

2) Search for the information/keywords appeared in the problem/requirement of the creation and add them in the Knowledge Space. If any information or any knowledge is unclear, more searches are needed for clarification.

3) Ideating relevant ideas in the Concept Space. The ideation can be done by using a mind map. When conducting the ideation, try to break down ideas or think of new ideas. Include both possible and impossible ideas.

4) Consider if the new ideas need any more information or knowledge and/or check the acceptance and feasibility of the new ideas by looking for additional information in the Knowledge Space. 
5) Summarize and stop thinking when the new ideas have been proved feasible and accepted by society under the condition that creative ideas are positive and novel ideas with no harm caused to oneself and others.

2. To adopt the C-K theory to develop creativity of the students, teacher should consider whether there is any obligation of any features of the creation or not. If the teacher wants the students to freely design their creation without any obligations, it is likely that using the ideas in the Knowledge Space can reduce the ideation of the Concept Space because the teacher doesn't want the students to attach their ideas only with the current existing knowledge. Knowledge is just a basis for ideation only.

\section{ACKNOWLEDGE}

I would like to express thankfulness to the Thailand Research Fund. With a mentoring system as part of the funding requirement, the study was under superb guidance from two experts: Assoc. Prof.Dr. Yothin Sawangdee and Asst. Prof. Sansern Milindasuta. Last but not least, I am also immensely grateful to Assoc. Prof. Dr. Vincent Ribiere, who provided expertise and suggestions that greatly assisted study.

\section{REFERENCES}

Barbot, B., Lubart, T. I., \& Besançon, M. (2016). Peaks, slumps, and bumps: Individual differences in the development of creativity in children and adolescents. New directions for Child and Adolescent Development, 151, 33-45.

Cole, D. G., Sugioka, H. L., \& YAMAGATA-LYNCH, L. C. (1999). Supportive classroom environments for creativity in higher education. The Journal of Creative Behavior, 33(4), 277-293.

De Stobbeleir, K. M., Ashford, S. J. \& Buyens, D. (2011). Self-regulation of creativity at work: The role of feedback seeking behavior in creative performance. Academy of Management Journal, 54, 811-832.

Gardner, H. (1993). Creating minds. New York: Basic Books.

Hallman, S., Wright, M. C., \& Conger, A. J. (2016). Development and assessment of student creativity. CRLT Occasional Paper No. 33. The University of Michigan.

Hatchuel, A., Le Masson, P., Weil, B., Agogué, M., Kazakçi, A., \& Hooge, S. (2016). Multiple forms of applications and impacts of a design theory: 10 years of industrial applications of CK theory. In A. Chakrabarti, \& U. Lindemann (Eds.), Impact of design research on industrial practice (pp. 189-208). Springer International Publishing.

Jaussi, K. S., Randel, A. E., \& Dionne, S. D. (2007). I am, I think I can, and I do: The role of personal identity, self-efficacy, and cross-application of experiences in creativity at work. Creativity Research Journal, 19(2-3), 247-258.

Karwowski, M., Lebuda, I., Wisniewska, E., \& Gralewski, J. (2013). Big five personality traits as the predictors of creative self-efficacy and creative personal identity: Does gender matter? The Journal of Creative Behavior, 47(3), 215-232. 
Kim, J., Kim, Y., Do, J., \& Heo, S. (2016). Development of CS couse for improving creativity based on CPS model-focusing on image-making. Training, 9, 97-101.

Kim, K. H. (2006). Can we trust creativity tests? A review of the Torrance tests of creative thinking (TTCT). Creativity Research Journal, 18(1), 3-14.

Kolberg, E., Reich, Y., \& Levin, I., (2007). Express engineering change management. In: CDROM proceedings of the 16th international conference on engineering design (ICED). Glasgow, Scotland: The Design Society.

Loudon, G., \& Deininger, G. (June, 2014). A new model for supporting creativity in research organizations. Paper presented at Management Conference, Stuttgart.

Oldham, G.R. \& Cummings, A. (1996). Employee creativity: Personal and contextual factors at work. Academy of Management Journal, 39, 607-34.

Osborn, A. (1953). Author applied imagination: Principles \& procedures of creative thinking. New York: Scribner.

Reich, Y., Hatchuel, A., Shai, O., \& Subrahmanian, E. (2012). A theoretical analysis of creativity methods in engineering design: casting and improving ASIT within $\mathrm{C}-\mathrm{K}$ theory. Journal of Engineering Design, 23(2), 137-158.

Renzulli, J. S. (2016). The role of blended knowledge in the development of creative productive giftedness. International Journal for Talent Development and Creativity, 13.

Renzulli, J. S. (2016). The three-ring conception of giftedness: A developmental model for promoting creative productivity. In S. M. Reis (Eds.), Reflections on gifted education: Critical works by Joseph S. Renzulli and colleagues (pp. 55-90). Waco, TX: Prufrock Press.

Ribiere, V. (2013). Knowledge-based innovation and design: C-K theory the process to innovation that changes. IKNOW. 3(2), 27-28.

Shibuya, T., et al. (October, 2013). Educational patterns for generative participants: Designing for creative learning. Proceedings of the 2013 Conference on Pattern Languages of programs.

Torrance, E. P. (1990). The Torrance tests of creative thinking norms-technical manual figural (streamlined) forms $A \&$ \& . Bensenville, IL: Scholastic Testing Service, Inc.

Torrance, E. P. (2008). Thinking Creativity with Words. Forms A and B. Bensenville, IL: Scholastic Testing Service. Inc.

Urupong Phaetkacha. (2017). Interviewed.

VandenBos, G. R. (2007). APA dictionary of psychology. American Psychological Association, Washington, D.C.

Wallas, G. (1926). The art of thought. New York: Harcourt Brace. 